\title{
"ARROZ DE TELHADOS": OS GESTOS AUTORAIS DE/EM ADILLA
}

\section{“ROOF RICE": THE COPYRIGHT GESTURES OF/IN ADILIA}

http://dx.doi.org/10.11606/issn.2175-3180.v12i22p76-93

Paulo Alberto da Silva Sales ${ }^{\mathrm{I}}$

\section{RESUMO}

A poesia performática de Adília Lopes causa nos leitores estranhamentos diversos pelo hibridismo típico de sua poética. São poemas que se servem de inúmeras referências, sejam relacionadas à vida da poeta e/ou a elementos intertextuais de fontes diversas. Nesses amálgamas, a questão da autoria fica latente, uma vez que não se constata uma "originalidade" em/de seus textos. No intuito de verificar como a figura autoral da poeta se esmaece no entrecruzamento de discursos diversos, apoiados nos estudos seminais de Barthes, Foucault, Agamben, dentre outros, apresentamos a leitura de alguns poemas presentes no livro Manhã, publicado em 2015, nos quais os processos de escrituras múltiplas evidenciam a ascensão de uma poética da leitura.

\section{PALAVRAS-CHAVE}

Autoria; Intertextualidade; Adília Lopes.

\section{ABSTRACT}

Adília Lopes' performative poetry induces her readers to much strangeness by the hybridism, typical of her poetry. Her poems make many references related to the poet's life and/or by intertextual elements of miscellaneous sources. In these amalgams the question of authorship is latent because one does not verify originality in/of her texts. In order to verify how the poet's authorial figure is faded by the lathing of several speeches and supported in seminal studies of Barthes, Foucault, Agamben and others we pretend to read some poems of the book Manhã, published in 2015, made by multiple scriptures that evidence a reading poetic.

\section{KEYWORDS}

Authorship; Intertextuality; Adilia Lopes.

\footnotetext{
I Instituto Federal Goiano, Hidrolândia, Brasil; Universidade Estadual de Goiás, Goiânia, Brasil.
} 
O autor marca o ponto em que sua vida foi jogada na obra. (AGAMBEN, 2007, p. 61)

A crítica literária do século XIX e do início do século XX lia a obra literária a partir da vida do autor. José Saramago, em um dos seus Cadernos de Lanzarote, afirmou: "O leitor não lê o romance. O leitor lê o autor". Foi sob essa perspectiva - a do autor enquanto autoridade e detentor dos "segredos" de sua obra - que se consolidou no romantismo a noção de originalidade por meio do "autor-presença" (HANSEN, 1993), cujas obras, por ele criadas, teriam a "aura" e a identidade do criador. O estruturalismo, em torno dos anos 1960, procurou "matar" esse autor e propôs o fim da hegemonia da autoridade desse sujeito externo à obra. Passou-se, então, a valorizar os sentidos e a imanência do texto literário em si, desconsiderando quaisquer elementos externos. Contudo, são datados dessa mesma década textos fundamentais da crítica literária contemporânea que norteariam, a partir de então, a relação entre sujeito e escrita enquanto forma e experiência, levando-se em consideração a problema da subjetividade.

Em 1968, Barthes apresenta seu estudo "A morte do autor" e, no ano seguinte, Foucault profere a palestra "O que é um autor?" que, posteriormente, seria transformada em livro. Tanto Barthes quanto Foucault trazem aspectos que serão repensados na crítica literária a partir de então: a indiferença no tratamento do autor como mote ou princípio fundamental da ética da escrita literária contemporânea, tendo em vista que, agora, "a escritura é a destruição de toda a voz, toda a origem. [...] é esse neutro, esse composto, esse oblíquo pelo qual foge o nosso sujeito, o branco-e-preto em que vem se perder toda identidade, a começar pela do corpo que escreve" (BARTHES, 2004, p. 57). Definida como uma linguagem intransitiva, lugar de polissemia, do intertexto e da significância - sobretudo referindo-nos à Julia Kristeva (2005) - a proposta 
da escritura presente em Le plaisir du texte (1973) de Barthes mostra-se transgressora ao inverter o sistema de seu interior. Por isso,

seu tempo é um presente voltado para o futuro, que ela anuncia e chama, ao forçar os limites contemporâneos a ela. Seu sujeito não é mais o antigo sujeito essencial ou consistente dos discursos representativos, racionais e psicológicos, mas um efeito do próprio texto, que o produz em instâncias provisórias, em processo (referências: Lacan e Kristeva). (PERRONE-MOISÉS, 2012, p. 83-84, grifos nossos)

Kristeva, apoiada nos estudos de Bakhtin e em consonância com o pensamento de Barthes e de Foucault, designaria a escritura, simultaneamente, como subjetividade e como comunicabilidade, ou como ela melhor teorizou, como "intertextualidade": "a noção de pessoa-sujeito da escritura começa a se esfumar para ceder lugar a uma outra, a da ambivalência da escritura" (KRISTEVA, 2005, p. 71, grifos no original). Em consonância às indagações de Barthes e de Kristeva, Foucault defende que o autor é uma "função" e que, por esta razão, está ligada aos sistemas legais e institucionais que determinam e articulam os diversos domínios discursivos. Logo, essa "autoridade" do texto não seria atribuída a um indivíduo concreto, haja vista que sua função dá lugar a múltiplos egos e várias posições subjetivas que podem ser ocupadas por qualquer indivíduo. $\mathrm{O}$ autor perde, então, a sua aura e seu nome serve para caracterizar um certo modo de ser do discurso porque, "de facto, todos os discursos que são providos da função autor comportam esta pluralidade de eus" (FOUCAULT, 2006, p. 55). Por meio da menorização do autor visto sob o prisma da origem, a reflexão arqueológica foucaultiana traz o foco de atenção na contemporaneidade para a escritura em si. Ao se apropriar da frase de Samuel Beckett - "Que importa quem fala, disse alguém, que importa quem fala"1 - oriunda do romance L'Innommable, de 1953, Foucault (2006, p. 35) entende que na escrita literária, "não se trata da manifestação ou da exaltação do gesto de escrever, nem da fixação de um

\footnotetext{
${ }^{1}$ Agamben (2007) retoma o texto "O que é um autor?" de Foucault e, a partir da proposta foucaultiana da função autor, o teórico italiano empreende a perspectiva de "autoria como gesto". A partir da citação de Beckett utilizada na palestra de Foucault, Agamben constata uma contradição: “Há, por conseguinte, alguém que, mesmo continuando anônimo e sem rosto, proferiu o enunciado, alguém sem o qual a tese, que nega a importância de quem fala, não teria podido ser formulada. O mesmo gesto que nega qualquer relevância à identidade do autor afirma, no entanto, a sua irredutível necessidade. (AGAMBEN, 2007, p. 55, grifo no original). Será por meio da perspectiva da autoria como gesto, associada às escrituras múltiplas, que leremos alguns poemas de Adília Lopes.
} 
sujeito numa linguagem: é uma questão de abertura de um espaço onde o sujeito de escrita está sempre a desaparecer".

Tendo, então, decretado a morte desse autor-presença, Barthes põe em evidência o nascimento do leitor crítico. Cabe, então, à écriture devolver a esse leitor o seu lugar e não mais condicionar a explicação da obra a quem a produziu porque "o autor nunca é mais do que aquele que escreve" e, então "esse sujeito, vazio fora da enunciação que o define, basta para "sustentar" a linguagem, isto é, para exauri-la" (BARTHES, 2004, p. 60). Sob essa perspectiva, Barthes entende que a posição do autor como proprietário de seu artefato é irrelevante para a explicação da obra. O texto literário assume a condição de jogo de escritura, ou seja,

o escritor moderno nasce ao mesmo tempo que seu texto; não é, de forma alguma, dotado de um ser que precedesse ou excedesse a sua escritura, não é em nada o sujeito de que seu livro fosse o predicado; [...] e todo texto é um aqui e agora. É porque (ou segue-se que) escrever já não pode designar uma operação de registro, de verificação, de representação, de "pintura" [...] mas sim [...] de performativo, forma verbal rara (usada exclusivamente na primeira pessoa e no presente), na qual a enunciação não tem outro conteúdo (outro enunciado) que não seja o ato pelo qual ela se profere. (BARTHES, 2004, p. 61)

Seja por meio da negação do autor enquanto origem ou na aceitação da função autor como um elemento da escritura que coloca em relevo a abertura e a multiplicidade de discursos que compõem o sujeito, a escrita performativa do aqui e do agora, do querer-escrever na primeira pessoa e no presente da escrita são elementos presentes em boa parte da obra da poeta Adília Lopes (1960 -). Autora de várias obras publicadas da década de 1980 aos dois decênios do século XXI, Adília tem articulado em seus textos possibilidades plurais e mistas de "autorretratos". Em seu livro Manhã, de 2015, há inúmeras inscrições de si mesma nos 102 poemas que compõem o conjunto da obra. Adília Lopes, pseudônimo de Maria José da Silva Viana Fidalgo de Oliveira, traveste-se de inúmeras máscaras nos seus poemas que remetem, por sua vez, a dados e elementos autobiográficos ${ }^{2}$. Contudo, veremos que seus discursos poéticos se metamorfoseiam em microrrelatos narrados por uma dicção simplista e, ao mesmo tempo irônica:

²Adília insere fotografias de si mesma datadas das décadas de 1960 e 1970 e as correlaciona aos seus poemas, colocando em xeque a dicotomia autobiografia versus poesia. 
NOVA YORK

Vivo na mesma casa em Lisboa há 54 anos. A casa tem 126 anos. A minha família vive nesta casa há 98 anos. Contei isso a um poeta americano que vive em Nova York. Disse-me que uma história assim era impossível em Nova York.

$16 / 8 / 14$

(LOPES, 2015, p. 43)

Em uma vasta teia intertextual, a autora se insere no texto poético em um jogo articulado por meio de remissões, correspondências, fotografias, relatos memorialísticos e por reconstituições de dados biográficos de familiares, sobretudo de informações relacionadas à mãe, à tia, à avó materna, ao avô materno, à bisavó e ao bisavô. Outros sujeitos citadinos de tempos passados, sobretudo ligados à infância e à adolescência, também são entrelaçados ao tempo presente da escrita poética pela voz do sujeito da escritura não definível que se manifesta, ao mesmo tempo, infantilizado e adulto. Veremos, a seguir, por meio da leitura de alguns poemas de Manhã como Adília cria "gestos" autorais de/em sua escrita por meio de uma rede infinita hipertextos e de informações que vão da literatura canônica ocidental às informações da cultura de massa do último quartel do século XX.

II.

Utilizado como parte do título deste ensaio, "Arroz de telhados" refere-se a um poema que trata de aspectos pouco "originais" que estão presentes no discurso poético de Adília. Tal título remete a nomes de espécimes da botânica, mais especificamente à família das plantas crassuláceas cujo formato de suas folhas lembra bagos de arroz. Esta imagem de um elemento do meio vegetal - possivelmente ensinada à poeta pelo contato com sua mãe que fora bióloga - fez o sujeito lírico associá-la a uma lembrança dos seus primeiros momentos de aprendizagem nos quais a autora começaria a balbuciar as primeiras palavras e relacionaria os nomes às coisas à sua volta. Abaixo, leem-se tais evidências: 


\section{BIOLOGIA}

A minha mãe dizia: «para morrer basta estar vivo». A minha mãe era bióloga. Estudou a vida inteira o envelhecimento e a morte das plantas.

$7 / 8 / 14$

(LOPES, 2015, p. 59)

\section{ARROZ DE TELHADOS}

Aqui é a porta (e faz-se menção de tocar na boca)

Aqui é a campainha (e toca-se com o indicador na ponta do nariz)

Aqui são as janelas (e faz-se menção de tocar nos

olhos)

Aqui é o telhado (e faz-se menção de tocar na testa)

Aqui são ervinhas puxa por elas (e puxa-se pelos

cabelos da testa)

A minha mãe fazia-me isto quando eu era pequena.

(LOPES, 2015, p. 123)

O que poderia ser reconhecida, a princípio, como uma descrição de gestos feitos por uma criança nos primeiros anos de vida e que, por essa razão, traria a figura da autora para o centro da experiência poética, logo é intercalada por informações que destoam de um relato puramente afetivo: "A minha mãe fazia-me isto quando eu era pequena". O último verso destoa dos anteriores porque é o único no qual se percebe marcas de subjetividade, mesmo que apontada sutilmente pela escolha do verbo "fazer" no modo indicativo do tempo pretérito imperfeito.

Em quase todos os poemas de Manhã, Adília se vale do tom irônico que elimina as fronteiras entre vida e arte, transformando seu texto em um mundo discursivo feito de histórias, de palavras e frases ouvidas de seus antepassados:

\section{SER JOVEM}

A minha avó materna era lindíssima. Mas, quando era adolescente, contou-me ela, um tio-avô que era médico disse-lhe:

- Tens um andar tão feio que não te casas.

E: 
- Tens um traseiro que pareces o Prior da Lapa.

$17 / 8 / 14$

(LOPES, 2015, p. 44)

Os discursos poéticos são organizados por uma memória textual que os confrontam com as redescrições de mundo. Para Rosa Maria Martelo (2010, p. 227), os poemas de Adília funcionam como espécies de "moinhos" que são movidos por águas passadas, sobretudo pela necessidade de revisitar e de reelaborar as memórias da infância. Manhã - cujo título metafórico se refere às primeiras impressões do dia como também pode fazer alusão às vivências infanto-juvenis - é o primeiro livro de uma trilogia ${ }^{3}$ de textos híbridos que trazem para o plano da lírica a figura da autora entremeada a tempos esquizóides que não se firmam, somente, à infância e à adolescência. O jogo da escritura se instaura em sua poesia aí: o devir-louco e a dobradura em si mesma, tal como entende Deleuze (1991), se manifesta em sua poesia por meio da "inflexão". Não há um sujeito autoral definido, mas sim, opondo-se à concepção cartesiana de sujeito, nota-se um ponto de vista sobre uma variação que venha a substituir o centro de uma figura ou de uma configuração, tal como se lê no poema abaixo:

\section{LER E ESTUDAR}

Aos 12 anos, pensei que na escola ia aprender a mitologia grega e o Antigo Egito. Nada disso. Ouvia falar do PIB e da lei de Malthus. Nada de Ísis nem de Osíris. Ainda não sabia como faziam os bebés, já ouvia falar do problema da demografia e do controlo dos nascimentos. Achei que, com o controlo dos nascimentos, podia não nascer o Mozart da demografia que resolvesse o problema da demografia. Era um tempo em que pensava que o mundo podia ser só imaginação minha. Disse isto a uma professora estúpida que me disse: Tinhas muita imaginação!

Estudava e lia continuamente, não havia folgas.

\footnotetext{
${ }^{3}$ Integram a trilogia iniciada pela obra Manhã os livros Bandolim e Estar em casa, publicados em 2016 e 2018, respectivamente. Em todos eles, a escrita poética articula elementos provenientes da autobiografia da autora que é mesclada a memórias discursivas diversas que são representadas, também, por moldes diferentes. A utilização do verso em prosa em formas de pequenas histórias é o aspecto formal mais evidente nos três livros. Somada à essa estratégia poética, são intercaladas citações, apropriações cenas de diálogos, histórias ouvidas, provérbios, citações em inglês e em francês, bem como o emprego de anedotas.
} 
Mesmo nas férias estabelecia horários para mim, estudava toda a matéria que tinha ficado por dar durante o ano lectivo, tinha os programas do Ministério. Fazia isto porque gostava de fazer isto, ninguém me obrigava. Na escola não sofria de surmenage, foi uma bênção. Sem liberdade não se aprende nada. Aos domingos de manhã estudava matemática e lia a História do mundo das publicações Alfa. Comecei a comprar os fascículos desde o primeiro na tabacaria da esquina. Pensava se começaria em Adão e Eva, se em Afonso Henriques. Não sabia bem o que havia entre Adão e Eva e Afonso Henriques. Discutia esta questão na cozinha com a criada. Ela também não sabia e também lhe fazia confusão. Vivíamos nos tempos dos livros de linhagens. A História do mundo das publicações Alfa não começou a ser publicada pelo primeiro volume. Começou por um volume adiantado que falava Knox e da Reforma protestante. Nunca tinha visto esta palavra escrita: Knox. Fiquei fascinada. Li tudo.

Entre os 15 e 18 anos li o Em busca do tempo perdido todo em francês. Comprei na Buchholz. Tinha uma ideia infantil: achava que de volume para volume o francês de Proust seria mais difícil e eu poderia não perceber. Só comprava um volume quando acabava de ler o volume anterior. Não tive dificuldades. Tinha o Petit Robert. Havia palavras que não vinham no Petit Robert. Não me afligi.

Aos 21 anos recorri a uma psicanalista estúpida. Contei-lhe que tinha lido o Em busca do tempo perdido. Ela me disse: Ainda não perdeu muito tempo! As professoras e as psicanalistas não leram livros. Percebi isto tarde. Não vale a pena.

Não foi por estudar muito e por ler muito que adoeci dos nervos aos 21 anos, foi por viver num ambiente deprimente. O que me valeu foi ter estudado e lido muito. Estudar e ler é quase o melhor que há.

$17 / 11 / 14$

(LOPES, 2015, p. 125-126)

"Ler e estudar" é o último poema de Manhã. Fica evidente que, nele, Adília cria um autorretrato de si mesma, funcionando como um gesto autoral da escritura. A poeta faz aquilo que Agamben (2007) entende como 
uma vida que foi jogada na obra e, por isso, o autor nada pode fazer "além de continuar, na obra, não realizado e não dito". Nesse sentido,

o gesto do autor é atestado na obra a que também dá vida, como uma presença incongruente e estranha. [...] Isso porque também a escritura [...] é um dispositivo, e a história dos homens talvez não seja nada mais que um incessante corpo-a-corpo com os dispositivos que eles mesmos produziram - antes de qualquer outro, a linguagem. E assim como o autor deve continuar inexpresso na obra e, no entanto, precisamente desse modo testemunha a própria presença irredutível, também a subjetividade se mostra e resiste com mais força no ponto em que os dispositivos a capturam e põem em jogo. Uma subjetividade produz-se onde o ser vivo, ao encontrar a linguagem e pondo-se nela em jogo sem reservas, exibe em um gesto a própria irredutibilidade a ela. (AGAMBEN, 2007, p. 63, grifos nossos)

Ao lado da configuração de gestos de autoria modulados pela linguagem, verifica-se o tom risível e cômico - muitas das vezes intencional - nos poemas adilianos. Arqueologicamente, à maneira foucaultiana, sua poesia reveste-se de camadas discursivas que exigem um trabalho de escavação. Em um primeiro contato, o leitor percebe um tom jocoso e mesmo antilírico que parece inclinar para um texto que denota uma conversa informal. Esse aspecto, que poderia revelar uma visão burlesca da vida, conduz o leitor, em uma segunda leitura, a uma reflexão sobre o estar-no-mundo contemporâneo que funciona como uma válvula de escape para que a poeta se autofabule na obra, ironizando a si mesma. Os dois poemas abaixo apresentam essas dubiedades entre o caricato e $o$ reflexivo presentes nas camadas dos versos:

\section{ANOS}

Aos 31 anos, passei quinze dias em Dublin.

Nessa altura, gostava muito do perfume C'est la vie! de Christian Lacroix. Usava esse perfume.

Numa esquina de Dublin, à porta de uma perfumaria havia um frasco de C'est la vie! quase do meu tamanho, meço 1,56m. Não sei se tinha alguma coisa dentro. Devia ter reparado.

(LOPES, 2015, p. 62) 


\section{MITO}

A escritora pobre remendada quase cega entrevada a sobreviver numa mansarda a alimentar-se de cevada e rabanetes a coser para fora alegremente a escrever romances à luz da lamparina não existe.

$15 / 8 / 14$

(LOPES, 2015, p. 42)

Nessas pequenas histórias nas quais as percepções sobre a vida se embaralham com a subjetividade lírica, Adília traz para o bojo da criação poética a figura do "escriptor" (BARTHES, 2004) contemporâneo, como sendo aquele que marca a cisão entre mundo interior e exterior, revertendo a ordem dos significantes desprovidos dos significados. Puzzles são arquitetados e nomes de personalidades históricas, literárias e teóricas passam a fazer parte do universo subjetivo da poeta:

\section{O SR. AFONSO}

O Sr. Afonso era o enfermeiro que me dava injecções em criança. Vinha a casa. Nunca me fez doer. Nunca tive medo de levar injecções graças ao Sr. Afonso. Eu imaginava, mas sabia que era uma fantasia, que o Sr. Afonso era o Afonso Henriques. Era D. Afonso Henriques que me dava injecções. Não conhecia mais Afonsos.

$26 / 8 / 14$

(LOPES, 2015, p. 54)

A nosso ver, no poema acima e grande parte dos outros pertencentes à Manhã, nota-se a expansão da poesia lírica e, também, a inadequação às categorias dos gêneros ao mesclarem elementos da prosa, principalmente à forma dos microcontos - "Era uma vez uma escritora tão poupada que/não escrevia para não gastar papel e tinta" (LOPES, 2015, p. 73) - e pela presença de uma dicção híbrida vinculada à memória e às vivências citadinas nas quais se verificam traços de uma crônica de costumes, tais como se leem em: "Casas pardas/ ruas tortas" (LOPES, 2015, p. 23) e em "Chego à janela porque preciso de ar e de árvo-/res. Ah, se não fosse esta velhinha janela onde/ me vou debruçar para ouvir a voz das cousas, eu/ 
não era a que sou" (LOPES, 2015, p. 108). O primeiro poema refere-se às impressões que o sujeito poético reconstituiu por meio de imagens de uma vila portuguesa localizada no distrito de Castelo Branco, no centro e na sub-região da baixa parte da província. Já o segundo faz um pastiche do poema "Canção duma sombra", de Teixeira de Pascoaes. A admiração pelo mentor do saudosismo português levou Adília a retomá-lo na epígrafe da obra Estar em casa, publicada em 2018: “Ah, se não fosse a névoa da manhã/ E a velhinha janela, onde me vou/ Debruçar, para ouvir a voz das coisas,/ Eu não era o que sou" (LOPES, 2018, p. 11).

Há também poemas que trazem apropriações de alguns ditados populares e trocadilhos típicos de pessoas comuns que provavelmente conviveram com a poeta, tais como em " «Ferva a água, sem no entanto a deixar ferver/ em cachão: o chá aprecia a calma!»/ Maria de Lourdes Modesto, A colher de pau" (LOPES, 2015, p. 85) e em:

\author{
Gosto das cebolas \\ e das pessoas \\ Mas as pessoas \\ são como as cebolas \\ fazem chorar
}

(dito por Maria de Lourdes Belchior)

(LOPES, 2015, p. 30)

III.

Como temos constatado, grande parte dos poemas são escritos nos moldes de pequenas narrativas ficcionais apresentadas por um narrador que mescla ora a primeira pessoa ora a terceira. Constroem-se no texto poético várias microbiografias de pessoas "desimportantes" às biografias tradicionais - no sentido empregado pela história total e/ou pela historia magistra vitae -, mas que, no caso da poética adiliana, são vitais. No poema "Miss Helen", Adília relaciona elementos biográficos, afetivos e memorialísticos a respeito de uma de suas primeiras professoras de língua inglesa às impressões de leitura do texto da escritora britânica Ágatha Christie - conhecida pelas suas narrativas do subgênero romance policial - e do filme $O$ caso paradine, de Alfred Hitchcock, de 1947, cujo enredo 
também articula um drama vivido por um advogado que se apaixona por sua cliente. A mélange dessas confluências resulta em um texto pluridiscursivo engendrado por hipotextos diversos:

\section{MISS HELEN}

Miss Helen deu-me explicações de inglês quando eu tinha 13-14 anos. Vivia na Rua de Macau, no Bairro das Colónias, com uma criada, que abria a porta. Na sala, estava pendurado o retrato da Rainha Isabel II.

Dava lições numa salinha pequena. Havia uma dúzia de livros, todos forrados, numa prateleira. Adorava films com tribunais. Nesse ano, de una Televisão O caso Paradine.

Tinha um método antiquado de ensinar inglês de que eu gostava. Nunca gostei dos métodos modernos, com diálogos e banda desenhada. Mandou-me comprar e forrar meia dúzia de cadernos. Um para ditados, outro para redacções, outro para verbos, outro para significados, etc.

Disse-me que eu conseguia ler Agatha Christie em inglês. Consegui.

Era velhíssima e fumava.

$17 / 6 / 14$

(LOPES, 2015, p. 16)

Esses mesmos poemas ainda reconstituem cenas de províncias portuguesas e costumes presentes no modus operandi de pessoas em suas vivências cotidianas com as quais a autora - Maria José - teve contato. Como uma espécie de "historiadora das mentalidades", Adília registra o modo de pensar de indivíduos de uma mesma época. O poema a seguir trata dessas reconstituições de costumes e de gestos:

\section{CASAMENTOS}

Uma coisa de que gosto muito no filme de Manoel de Oliveira Singularidades de uma rapariga loura é do namoro da janela. O namoro da minha Avó Zé foi assim, contou-me ela. A minha Avó Zé nasceu em 1901. Foi a criada que 
que lhe disse quando ela tinha 14 anos:

- Aquele menino aqui defronte olha muito para a menina.

Viviam na Baixa ou no Bairro Andrade.

Uma prima ou amiga dos meus bisavós foi lá a casa e disse:

- Há um rapaz Viana que quer namorar a Maria José. Esse está muito bem. Agora há um João Evangelista que quer namorar a Maria dos Anjos. Esse de maneira nenhuma.

Foi assim que a minha avó se casou com o meu avô.

A Maria dos Anjos era uma prima da minha Avó pela idade dela. Não se casou com o João Evangelista.

Da minha janela à tua vai o salto de uma cobra quem me dera chamar à tua mãe minha sogra. Dizia-me a minha avó.

O meu avô em criança vivia na Baixa. Atirava os brinquedos para a rua. Na rua estava sempre um galego que apanhava os brinquedos e os devolvia. Espero que o galego não tivesse de subir as escadas, acho que era um terceiro andar. Espero que a criada deixasse cair uma cesta presa por uma corda.

Ainda sou do tempo em que os ceguinhos passavam na rua a tocar a Madalena Iglésias. Atirava-se uma moeda embrulhada num bocadinho de papel.

(LOPES, 2015, p. 101-102)

O hibridismo de gêneros e de discursos - sejam eles literários ou não - é latente no livro Manhã. Tal mescla se constitui por meio de vários níveis intertextuais, tais como pela citação, pela apropriação, pela estilização e pela paródia (tanto no sentido crítico quanto da transcontextualização de códigos com distância crítica). Há a recorrência do emprego de nomes de escritores, de poetas e de teóricos da literatura em seus poemas, formando uma poética de/sobre a leitura. Nos poemas abaixo, a autora joga com referenciais literários e autobiográficos, ou melhor, significantes desprovidos de seus sentidos primeiros - e os coloca em um mesmo plano, que é o das memórias: 


\section{LEITURA}

A Condessa Gouvarinho cheirava a verbena e era ruiva. Verbena é lúcia-lima. Mas "a Condessa Gouvarinho cheirava a lúcia-lima" não é a mesma Coisa. Não há sinónimos.

Não tenho a certeza de que verbena e lúcialima seja a mesma coisa, isto é, a mesma planta, o mesmo cheiro.

$7 / 8 / 14$

(LOPES, 2015, p. 55)

\section{DIABETES}

Pico os dedos duas vezes por semana com uma espécie de pistola. A pistola tem uma lanceta. Seta que se espeta em quem a disparou escrevi eu há muito tempo a pensar numa batalha que vem n'Os Lusíadas em que isso acontece. É no Canto Segundo estrofe 49.

Desisti de picar os dedos assim. Era difícil. Vou picar os dedos à farmácia.

$12 / 8 / 14$

(LOPES, 2015, p. 37)

$\mathrm{Na}$ infinitude de referências presentes nos discursos adilianos, é recorrente a citação de nomes de escritores e de poetas - tais como os de Sophia/Sofia (referência à poeta Sophia de Mello Breyner Andresen), Condessa de Ségur (Sophie Feodorovna Rostopchine), Rimbaud, Goethe, Fernando Pessoa, James Joyce - bem como nomes de teóricos e de críticos literários, tais como os de Roland Barthes e da estudiosa de sua obra Rosa Maria Martelo. Aliás, a proposta de escrita de Adília é fortemente vinculada à perspectiva dos textes scriptibles de Barthes (1991). Nota-se uma rede plural de discursos que abre o texto à perspectiva do "jogo infinito do mundo". Os poemas em prosa possuem discursos polissêmicos com várias aberturas a redes nos empregos de linguagens. Nesses textos "ideais", "as redes são múltiplas e jogam entre si sem que nenhuma delas possa encobrir as outras; esse texto é uma galáxia de significantes e não uma estrutura de significados" (BARTHES, 1991, p. 13). O poema "Peras" trata dessa abertura do jogo infinito presente no texto escriptível barthesiano. Aliás, o 
próprio autor de Le degrée zero de l'écriture é convocado a integrar às múltiplas redes significativas e, por meio dessa hipermediação, são levantadas dúvidas sobre questões biográficas de Barthes em uma mistura de referências literárias:

\section{PERAS}

$\mathrm{N}^{\prime}$ As meninas exemplares, a Sofia d'Os desastres de Sofia rouba peras porque tem fome, a madrasta não lhe dá de comer. Sofia é castigada por ser lambareira e ladra. Eu, em criança, não percebia como é que se podia gostar de peras. Percebia que se roubassem bolos de chocolate e folhados de salsicha, peras não. Não gostava da fruta. De peras não gostava. Anos mais tarde, li Barthes. Barthes diz que gostava de peras e gostei a gostar de peras. Barthes pode estar a mentir. O poeta é um fingidor. Mas acho que Barthes não está a mentir quando diz que gosta de peras.

\section{$2 / 8 / 14$}

(LOPES, 2015, p. 74)

Nesse tipo de poesia, tudo é vida. Traços autobiográficos e biográficos são transfigurados pela arte e não há uma separação entre arte e não-arte. Não se trata, contudo, de uma poética confessional, tendo em vista que seus textos não tratam de forma dicotômica vida versus obra. Adília articula em sua linguagem poética elementos do universo familiar e dos fatos vividos no sentido da potência transformando-os em uma escrita pulsante. A autora mostra-se, também, profundamente arraigada aos fenômenos artísticos e culturais da era pós-moderna, sobretudo aos da pop art. No poema "Let's dance", por exemplo, o sujeito lírico faz intertextualidade com outras formas artísticas ao se valer de um dos maiores sucessos da música pop dos anos 1980, de autoria do inglês David Bowie e, também, do filme The barefoot contessa, proveniente do cinema pop dos anos 1950. Desse filme, Adília faz menção à personagem Maria Vargas, interpretada pela atriz norte-americana Ava Gardner, para, então, exprimir gestos autorais por meio de um descontentamento da poeta frente às normas estabelecidas pela sociedade do consumo: 


\section{LET'S DANCE}

Put on your red shoes and dance the blues cantava David Bowie em 1983.

Não é preciso os red shoes. Gosto mais de dansar descalça como Ava Gardner.

$12 / 8 / 2014$

(LOPES, 2015, p. 36)

Por fim, fluidas e feitas de dobraduras em si mesma, as várias "identidades" presentes na autora Adília se registram em seu texto por meio de simulações de "um real sem origem nem realidade", ou seja, tratam-se de construções hiper-reais nas quais há um "produto de síntese irradiando modelos combinatórios num hiperespaço sem atmosfera" (BAUDRILLARD, 1991, p. 8). Logo Adília, em sua poesia, cria várias fabulações de si mesma por meio de discursos que fazem essa poeta nascer no/pelo texto. Com os dois poemas intitulados "Vazio", damos cabo, por hora, à nossa leitura sobre as sutilezas dos gestos da escritura poética em/de Adília:

\section{VAZIO}

Aos 21 anos, a minha fotografia no bilhete de identidade sofreu uma reacção química, a minha cara desapareceu, ficou uma mancha castanha.

Aos 39 anos, comprei um perfume na farmácia. Devia estar lá há muito tempo, não cheirava a nada.

$10 / 8 / 14$

(LOPES, 2015, p. 68)

\section{VAZIO}

Uma vez, num texto, falei em esgrimir no vazio. É uma questão de física. Não sei o que é manejar um florete sem a resistência do ar. Não é fácil imaginar o vazio. Talvez esgrimir no vazio seja um disparate.

(LOPES, 2015, p. 67) 


\section{REFERÊNCIAS}

AGAMBEN, Giorgio. O autor como gesto. In: Profanações. Tradução Selvino José Assman. São Paulo: Boitempo, 2007, p. 55 - 63.

BARTHES, Roland. A morte do autor. In: O rumor da língua. Tradução Mário Laranjeira. São Paulo: Martins Fontes, 2004, p. 57 - 64.

BARTHES, Roland. O prazer do texto. Tradução J. Guinsburg. São Paulo: Perspectiva, 2010.

BARTHES, Roland. S/Z. Tradução Maria de Santa Cruz e Ana Mafalda Leite. Lisboa: Edições 70, 1999.

BAUDRILLARD, Jean. Simulacros e simulação. Tradução Maria João da Costa Pereira. Lisboa: Relógio D'Água, 1991.

BECKETT, Samuel. O inominável. Tradução Ana Helena Souza. São Paulo: Globo, 2009.

DELEUZE, Gilles. A dobra: Leibniz e o Barroco. Tradução Luiz B. L. Orlandi. Campinas/SP: Papirus, 1991.

FOUCAULT, Michel. O que é um autor? Tradução António Fernando Cascais. Lisboa: Vega, 2006.

HANSEN, João Adolfo. Autor. In: JOBIM, José Luís. (Org.). Palavras da crítica. Rio de Janeiro: Imago, 1993.

KRISTEVA, Julia. Introdução à semanálise. Tradução Lúcia Helena França Ferraz. São Paulo: Perspectiva, 2005.

LOPES, Adília. Bandolim. Porto: Assírio \& Alvim, 2016.

LOPES, Adília. Estar em casa. Porto: Assírio \& Alvim, 2018.

LOPES, Adília. Manhã. Porto: Assírio \& Alvim, 2015.

MARTELO, Rosa Maria. As armas desarmantes de Adília Lopes. In: A forma informe: leituras de poesia. Lisboa: Assírio \& Alvim, 2010, p. 235-252.

MARTELO, Rosa Maria. Contra a crueldade, a ironia. In: A forma informe: leituras de poesia. Lisboa: Assírio \& Alvim, 2010, p. 223-234.

PERRONE-MOISÉS, Leyla. Com Roland Barthes. São Paulo: Martins Fontes, 2012. 
O AUTOR NA POESIA MODERNA E CONTEMPORÂNEA

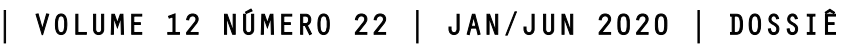

Recebido em 20 de junho de 2020

Aprovado em 22 de setembro de 2020

\section{Licença: (c) (†)}

Paulo Alberto da Silva Sales

Doutor em Letras e Linguística (Estudos Literários) pela Universidade Federal de Goiás, Brasil. Diretor da Unidade de Pesquisa e Pós-Graduação do Instituto Federal Goiano, Campus Hidrolândia, Goiás, Brasil. Docente do Instituto Federal Goiano e do Programa de Pós-Graduação Stricto Sensu em Língua, Literatura e Interculturalidade (POSLLI) da Universidade Estadual de Goiás, Campus Cora Coralina, Goiás, Brasil.

Contato: paulo.alberto@ifgoiano.edu.br

(iD) https://orcid.org/0000-0001-9980-2561 